\title{
Advances in Nephelometry through the Ecotech Aurora Nephelometer
}

\author{
Steve Chamberlain-Ward and Felicity Sharp \\ Ecotech Pty Ltd, 1492 Ferntree Gully Road, Knoxfield 3180, VIC, Australia \\ Received 27 October 2011; Accepted 16 December 2011 \\ Academic Editor: Richard Brown
}

The challenge for instrument manufacturers is to continuously improve and evolve their instrumentation to keep pace with scientific research. One field where this is evident is atmospheric aerosol research. The variety in aerosol size, shape, chemical composition, and their ability to change properties under varying atmospheric conditions creates many challenges in quantifying their impact on the global energy balance. As such a wide variety of instrumentation from a selection of manufacturers are used for analysing aerosols, all of which provide a little extra information for deciphering the puzzle. Recent advancements in commercial nephelometers by Australian manufacturer Ecotech have helped to piece some more of this puzzle together. This paper will detail these advances.

KEYWORDS: nephelometer, light scattering, atmospheric aerosol, angular scattering 


\section{WHY INVESTIGATE AEROSOLS?}

Considerable research is being undertaken to understand the impact that aerosols have in the global radiation balance. Radiative forcing is defined as the "change in net irradiance at the tropopause after allowing for stratospheric temperatures to readjust to radiative equilibrium, but with surface and tropospheric temperatures and state held fixed at the unperturbed values." [1].

In other words, radiative forcing is the imbalance between incoming solar radiation and outgoing infrared radiation which causes a change in the earth radiative balance. This imbalance causes changes in global temperatures. The IPCC report suggests a linear relationship between the global mean equilibrium surface temperature changes and the amount of radiative forcing.

Aerosols impact on radiative forcing is still not fully understood due to a variety of reasons including the dynamic nature and short life of aerosols in the atmosphere. Aerosols have both a direct impact on incoming radiation by scattering and absorbing solar and thermal radiation and also an indirect effect through cloud development, cloud albedo changes and precipitation occurrence [2].

\section{NEPHELOMETRY: FUNCTIONALITY}

The nephelometer has been commercially available for forty years with MRI/Belfort first marketing the 1550, 1560, and 1590 series of nephelometers. In recent times TSI Inc. has dominated the market with their nephelometer. A comparison between the TSI and Ecotech nephelometers has recently been conducted by Müller et al. [3].

Integrating nephelometers directly measure the light scattered by aerosols and gases in an enclosed sample volume. Figure 1 shows the Ecotech Aurora nephelometer inside the outer case. The sampling chamber and light source are confined to a small volume so that the instrument makes a "point" or localised measurement of scattering, continuously and in real time. The total measurements are then combined with a backscatter measurement that will only sample between $90^{\circ}$ and $170^{\circ}$ to give a more in-depth analysis of particle scattering. This information can be combined with data measured by other aerosol instruments and then inserted into mathematical models to derive the following additional parameters.

\subsection{Aerosol Asymmetry Parameter (g)}

It is defined as the cosine-weighted average of the phase function, where the phase function is the probability of radiation being scattered in a given direction. It can be derived, under certain assumptions, from the measured backscatter fraction [4].

\subsection{Angstom Exponent ( $(\AA)$}

It can be used to describe the dependency between aerosol optical depth and wavelength. The Angstrom exponent is inversely related to the average size of aerosol particles: the smaller the particles, the larger the exponent. Its determination using integrating nephelometers and satellite data provides valuable information into the optical depth of the atmosphere and the radiative forcing effect of aerosol.

\subsection{Single Scattering Albedo}

It is the ratio of light scattering to light extinction by atmospheric particles. It is an important parameter when assessing the climatic effects of aerosols. It is understood that aerosols with a single-scattering albedo greater than 0.85 generally cool the planet, while those with less than 0.85 warm the planet [5]. This is also dependent on the surface albedo and the backscatter fraction. 


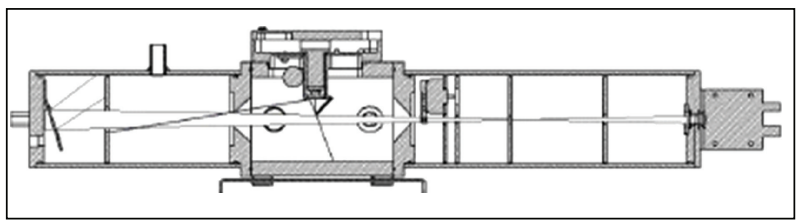

FIGURE 1: Illustration of the Aurora 3000 nephelometer.

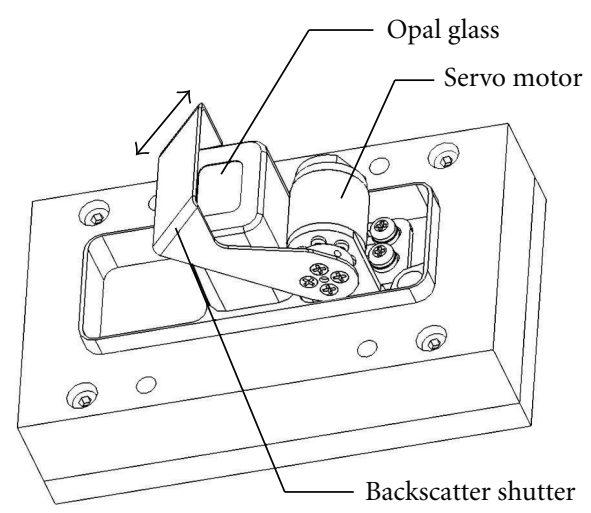

FIGURE 2: LED light source with backscatter shutter.

\section{THE AURORA SERIES OF NEPHELOMETERS}

Several classes of Ecotech nephelometer are available.

(i) Aurora 1000: It measures the scattering coefficient for a single wavelength and hence derive visibility measurements for Australian EPA.

(ii) Aurora 3000: It is a multiple wavelength instrument capable of providing information on total scatter as well as backscatter for various wavelengths of light.

(iii) Aurora 4000: It is an instrument capable of measuring aerosol scattering at a variety of different angles.

(iv) Aurora 5000 wet/dry: It is a system of two nephelometers with humidity control and comparison from the one sample stream.

These models have evolved with the following $R \& D$ advances.

\section{LED OPAL DIFFUSER}

The light source is a patented LED opal glass light source which was designed for the Aurora range of nephelometers as it achieves a lambertian distribution as close as possible to ideal (light intensity is the same in every direction) (see Figure 2). With rapid improvements in LED technology, it has been possible to obtain higher intensity outputs from smaller LED packages, and, as such, the light source has just 3 LEDs for each wavelength. It is preferable over the older flash lamp technology for several reasons.

LED light sources generate a fraction of the heat generated by halogen flash lamps. This is a critical element when considering the impact that temperature and humidity can have on hygroscopic aerosols.

The LED light source is extremely robust and reliable and has been demonstrated to last well in excess of 5 years without replacement. Halogen lamps are recommended for replacement every 6 months. 


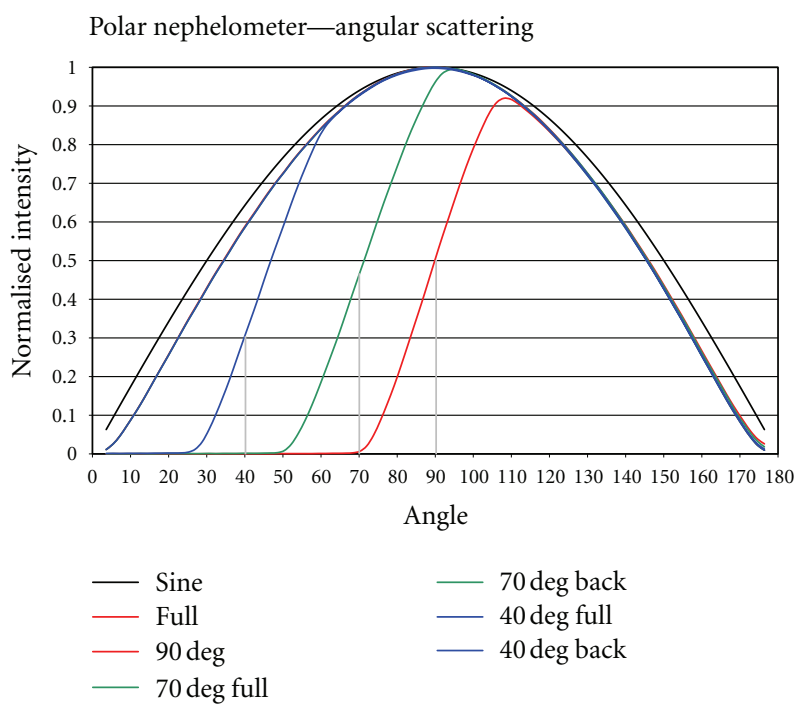

FIGURE 3: Graphical demonstration of backscatter measurements at $40^{\circ}, 70^{\circ}$, and $90^{\circ}$.

Considering the remote location of some integrating nephelometers, this reduction in maintenance is very significant.

The LED array also eliminates the need for narrow bandpass optical filters due to the LEDs intrinsic wavelength selectivity.

These enhancements in nephelometer technology have improved the reliability, intensity, and consistency of the light and thus the stability and performance of the instrument.

\section{POLAR NEPHELOMETER: ANGULAR SCATTERING}

Due to the irregular, nonspherical shape of some aerosols, the desire to incorporate angular scattering data into the standard total and backscatter data was acknowledged. Intensive R\&D has resulted in the latest advancement of the nephelometer into a commercially available polar nephelometer. The backscatter shutter can be set to any angle between 10 and $90^{\circ}$ at up to 17 different positions (see Figure 3 ). When the backscatter shutter is positioned at a specific angle, the nephelometer measures the light scattering from that angle to $170^{\circ}$. For example, a scattering angle set to $20^{\circ}$ will measure all scattering between $20^{\circ}$ and $170^{\circ}$. A scattering angle set to $30^{\circ}$ will measure all scattering between $30^{\circ}$ and $170^{\circ}$. Thus, the difference between these two angles will give the light scattering for the polar segment of $20^{\circ}$ to $30^{\circ}$. Each measurement cycle also includes a measurement without the backscatter active or a $0^{\circ}$ angle measurement. This is the first commercially available instrument of its type and is receiving a great deal of attention from researchers who recognise its potential for studying the light scattering effects of aerosols and its ability to improve the derivation of the aerosol asymmetry parameter $(\mathrm{g})$. Analysing smaller angles will also offer a greater understanding of the particle size.

\section{HUMIDITY SYSTEM}

Ambient humidity has a significant effect on the scattering effects of hygroscopic particles. Typically, the higher the humidity, the greater the scattering effect. Radiative forcing data needs to be compared at the ambient humidity levels, however in order to compare the scattering effect of aerosols globally, Global Atmospheric Watch Programme (GAW) recommends that the relative humidity is less than $40 \%$. 
Climate change modelling relies upon the aerosol asymmetry parameter, but most assume it to be 0.7 . Aerosol source, seasonal variation, and changes in relative humidity influence the number, size, and shape of aerosols and therefore affect the aerosol asymmetry parameter [4]. For instance a change of relative humidity (RH) between $40 \%$ and $85 \%$ will influence this parameter by up to $20 \%$.

Combining both the polar nephelometer and the ability to compare ambient humidity with a stepping gradient is a powerful new tool to gain further information on the aerosol coating and its properties.

\section{ROBUST FULLY INTEGRATED INSTRUMENT PACKAGE}

The Aurora series provides a fully integrated package that includes a measurement system, sample pump, calibration valves, data logger, and sample inlet heater in a compact low-power instrument. The use of LEDs in the light source has significantly reduced the power demand of this instrument to less than 15 watts without heater and to no more than 60 watts with the heater fully active. The instrument was designed to be easily installed and operated.

The instrument was designed to be extremely robust, not requiring air conditioning, and capable of experiencing high altitudes without interfering with its operation. It has worked successfully in ambient temperatures as high as $45^{\circ} \mathrm{C}$ and as low as $-20^{\circ} \mathrm{C}$. It has withstood pressures experienced at altitudes of $10,000 \mathrm{~m}$ and continues to operate in traffic tunnels when exposed to a very high level of diesel particulates.

It can be operated unattended for long periods of time with its automatic calibration system and can have its data easily downloaded using the Ecotech remote communication, validation, and reporting software. The calibration is very straightforward, with internal span and zero valves allowing calibration gas and zero air to pass into the cell for calibration, all of which can be set up in the menu system.

These features will enable the integrating nephelometer to be installed and reliably operated in a greater number of locations and in more inhospitable locations around the earth, providing information from these regions not previously available to researchers.

\section{CONCLUSION}

Technology manufacturers must continue to challenge their products and evolve in order to keep pace with science and the research that is being undertaken.

The Aurora Integrating Nephelometer series demonstrates how a small Australian company, not previously active in aerosol atmospheric science, but willing to learn and listen to experts from around the world, has managed to produce a series of instruments that challenge the status quo.

The development and success of the Aurora series has introduced Ecotech to new markets and customers and established Ecotech as a company able to innovate and produce reliable instrumentation that will be accepted and used by the world leading experts in atmospheric research.

\section{REFERENCES}

[1] S. Solomon, D. Qin, M. Manning et al., Climate Change 2007: The Physical Science Basis. Contribution of Working Group I to the Fourth Assessment Report of the Intergovernmental Panel on Climate Change, IPCC, Cambridge University Press, Cambridge, UK, 2007.

[2] S. J. Ghan and S. E. Schwartz, "Aerosol properties and processes: a path from field and laboratory measurements to global climate models," Bulletin of the American Meteorological Society, vol. 88, no. 7, pp. 1059-1083, 2007.

[3] T. Müller, M. Laborde, G. Kassell, and A. Wiedensohler, "Design and performance of a three-wavelength LEDbased total scatter and backscatter integrating nephelometer," Atmospheric Measurement Techniques, vol. 4, pp. 1291-1303, 2011.

[4] J. A. Ogren, E. Andrews, A. McComiskey, P. Sheridan, A. Jefferson, and M. Fiebig, "New insights into aerosol asymmetry parameter," in Proceedings of the 16th ARM Science Team Meeting, Albuquerque, NM, USA, 2006. 
[5] J. Hansen, D. Johnson, A. Lacis et al., "Climate impact of increasing atmospheric carbon dioxide," Science, vol. 213, no. 4511, pp. 957-966, 1981.

This article should be cited as follows:

Steve Chamberlain-Ward and Felicity Sharp, "Advances in Nephelometry through the Ecotech Aurora Nephelometer," TheScientificWorldJOURNAL, vol. 11, pp. 2530-2535, 2011. 

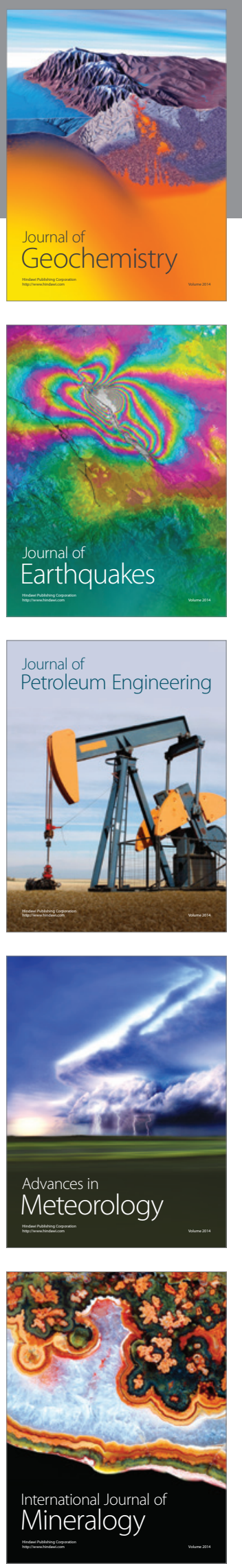
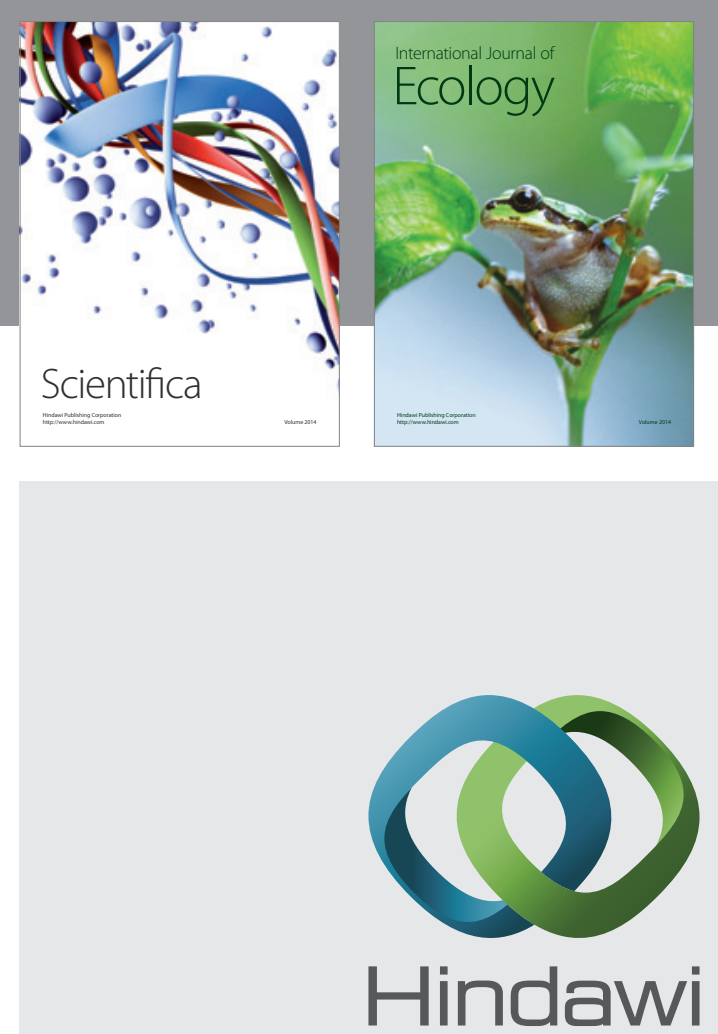

Submit your manuscripts at http://www.hindawi.com
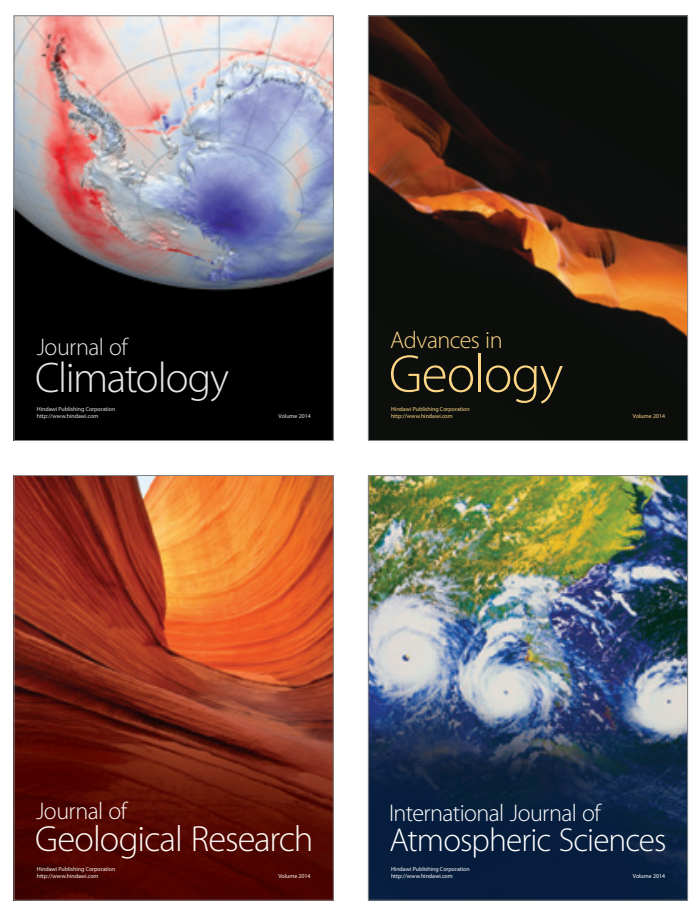
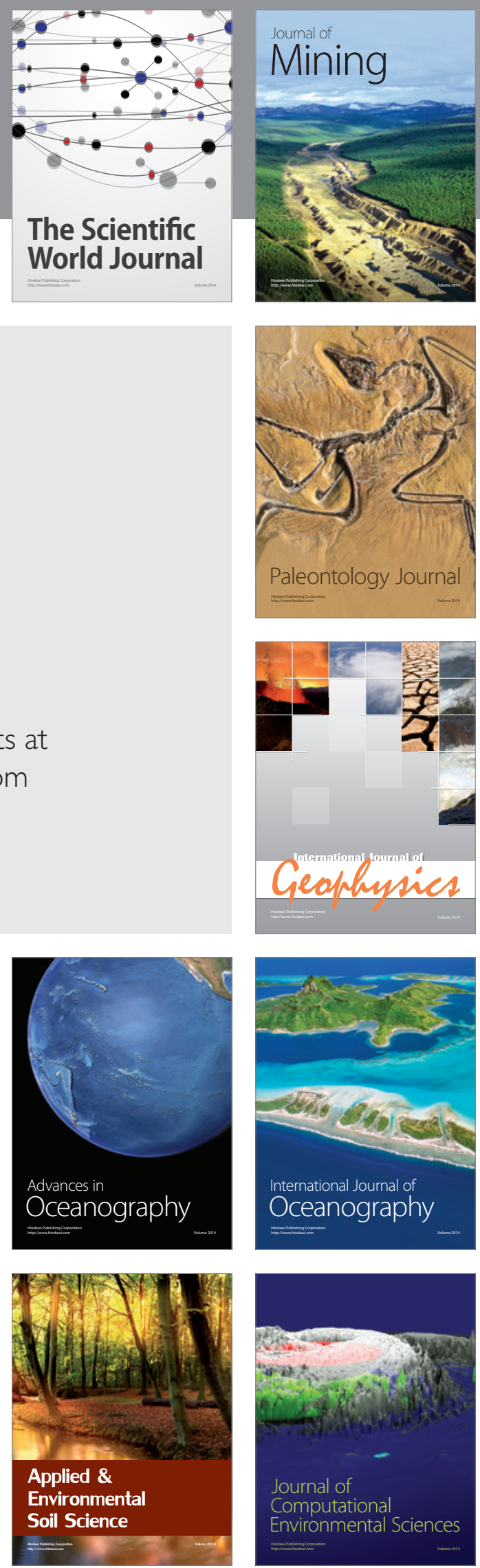